\title{
Практики «открытых инноваций» в России: эмпирическое исследование инновационного поведения предприятий Пермского края.
}

\begin{abstract}
Быкова А.А. ${ }^{49}$, Молодчик М.А. ${ }^{50}$
В статье представлень результаты исследования, посвященного анализу влияния межфирменного взаимодействия в сфере НИОКР на показатели финансовой результативности фирм. На основе анализа существующих эмпирических исследований были выделены факторы кооперации и проведен регрессионный и коррелящионный анализ для выборки из 401 компаний Пермского края. Результаты показали, что полученные выводы в целом соотносятся $c$ зарубежными и российскими эмпирическими исследованиями. Некоторые факторы кооперации (участие в региональных БизнесАссоциациях, затрат на НИОКР, расположенность в пределах агломерации) на данной выборке оказывают значимое влияние на результативность деятельности компаний. Тем не менее, такой эффект достаточно слаб, а такие показатели как участие в совместных инновационных проектах оказались не значимыми во всех построенных моделях.
\end{abstract}

JEL: G32

Ключевые слова: внешние эффекты знаний, открытые инноващии, стратегические альянсы, инновационные кластеры, межфирменное взаимодействие, количественная оценка факторов кооперации.

\section{Введение}

Анализ роли внешних эффектов знаний (knowledge spillovers), их влияния на стратегию поведения компании в настоящее время стал одним из главных объектов интереса со стороны экономистов, изучающих природу инноваций и экономического роста [Grant, 1996; Tеece, 2000].

Начиная с работ Й. Шумпетера, большинство исследований в этой области можно разделить на два направления. Во-первых, это работы, анализирующие структурные и отраслевые характеристики фирмы (уровень расходов на НИОКР, затраты на человеческий капитал, размер фирмы, отраслевая специализация и т.д.) и способствующие внедрению инноваций. Во-вторых, это исследования в области анализа свойств внешней среды и особенностей, возникающих в связи с наличием специфических ресурсов у различных фирм на определенной территории (развитая инфраструктура, наличие объектов поддержки бизнеса, образовательных учреждений, исследовательских центров и т.д.).

Современные исследования влияния специфичных знаний фирмы на ее конкурентоспособность являются результатом эволюции взглядов на теорию фирмы (табл. $1)$.

\footnotetext{
${ }^{49}$ Научный сотрудник Лаборатории инвестиционного анализа ПФ ГУ-ВШЭ, аспирант 2 года Института анализа предприятий и рынков ГУ-ВШЭ, преподаватель кафедры экономической теории ПФ ГУ-ВШЭ.

${ }^{50}$ К.э.Н., доцент кафедры экономической теории ПФ ГУ-ВШЭ
}

Выпуск \#3(11), 2009

() Электронный журнал Корпоративные Финансы, 2009 
Эволюция взглядов на теорию фирмы*

\begin{tabular}{|c|c|c|}
\hline $\begin{array}{c}\text { Подход к анализу } \\
\text { фирмы }\end{array}$ & Авторы & Фактор успеха \\
\hline $\begin{array}{l}\text { Ресурсно- } \\
\text { ориентированная } \\
\text { теория } \\
\end{array}$ & $\begin{array}{c}\text { Penrose, 1959; Barney, } \\
1986\end{array}$ & $\begin{array}{l}\text { Набор трудно имитируемых ресурсов } \\
\text { («липких»). Фирма прилагает усилия по их } \\
\text { защите и своего положения на рынке }\end{array}$ \\
\hline $\begin{array}{c}\text { Теория динамических } \\
\text { способностей }\end{array}$ & $\begin{array}{l}\text { Teece \& Pisano, and } \\
\text { Shuen, } 1997\end{array}$ & $\begin{array}{l}\text { Совокупность специфичных } \\
\text { постоянно изменяющихся в ответ на } \\
\text { изменения внешней среды. Фирма } \\
\text { занимается их созданием и улучшением }\end{array}$ \\
\hline $\begin{array}{c}\text { Теория, основанная на } \\
\text { знаниях }\end{array}$ & $\begin{array}{l}\text { Nahapiet \& Ghoshal, } \\
1998 \\
\text { Nonaka \& Takeuchi, } \\
\text { 1995; } \\
\text { Chesbrough, } 2003\end{array}$ & $\begin{array}{l}\text { Знания и } \\
\text { интегрировать их в бизнес-процессы } \\
\text { компании. Фирма развивает их путем } \\
\text { взаимодействия с внешними источниками } \\
\text { знаний }\end{array}$ \\
\hline
\end{tabular}

*Сост. по: [Torbett, 2001].

Главным фактором успешности фирмы, согласно двум последним теориям, является приобретение новых знаний и способностей посредством постоянного взаимного обучения. Многие авторы [Hagedoorn \& Schakenraad, 1990; Eisenhardt \& Schoonhoven, 1996; Trott \& Hartmann, 2008] описывают процесс обучения как новую парадигму функционирования компании: переход от закрытой к открытой инновационной модели развития [Raasch Ch., 2008]. В этом контексте особую значимость приобретает изучение различных форм и практик кооперативного инновационного поведения, таких как стратегические альянсы и инновационные кластеры [Chesbrough, 2006; McCann \& Iammarino, 2006; Lundvall, 1992; Audretsch \& Feldman, 1996].

За некоторым исключением, объяснения того, почему фирмы становятся участниками стратегических альянсов, напрямую связаны с предположениями о наличии выгод для их участников [Walker, Kogut and Shan, 1997]. Исследования демонстрируют, что участие в альянсах помогает фирмам:

- создавать и абсорбировать новые технологии [Ahuja, 1998],

- противостоять внешним шокам экономики [Miner, Amburgey and Stearns, 1990],

- улучшать позиции на рынке и финансовые результаты ]Baum et al., 2000],

- обучаться новым навыкам [Powell et al., 1996; Hagedoorn and Schakenraad, 1994; Hollenstein, 2001].

Инновационные кластеры могут рассматриваться в качестве одного из современных подходов к «открытым инновациям», поскольку предполагают, что инновации создаются конкурирующими фирмами в кооперации с учреждениями исследовательского сектора университетами, научными центрами ${ }^{51}$ в условиях формирования региональной инновационной системы. Такая концепция получила название «тройной спирали» (triple helix) [Hollenstein, 2001]. Как отмечает МакКендрик [McKendrick, 2001], анализируя отрасль жестких дисков в США, именно в кластере конкурирующие компании идут на сотрудничество. Конкуренция среди фирм внутри кластера позволяет не только исключить слабых участников, но и стимулирует всех к инновациям и кооперации. Также кластерная форма организации более предпочтительна по сравнению с другими с точки зрения вероятности появления внешних эффектов знаний среди близкорасположенных фирм

\footnotetext{
51 Ряд исследователей называют такой процесс co-opetiton - от объединения «competition» и «cooperation», как основную характеристику таких форм сотрудничества [Cipolla, Cavalcanti and de Castro, 2006].
} 
[Hollenstein, 2001]. Как отмечает А. Саксениан [Saxenian, 1994], именно такой способ распространения идей и инноваций (автор сравнивает его с перекрестным опылением crosspollination), рассматривается как один из главных драйверов успеха Силиконовой долины и ИКТ-кластера Стокгольма.

Тем не менее, кроме преимуществ, и кластеры, и стратегические альянсы не всегда бывают успешными в связи с наличием «помех в практическом применении», возникающих из-за:

- сложностей в поиске равноценных партнеров для кооперации;

- юридических или финансовых трудностей;

- отсутствия доверия между партнерами и вовлеченными институтами;

- завышенных ожиданий от участия [Etzkowitz and Leydesdorff, 2000].

Кроме этого, несмотря на схожесть мнений о том, что различные формы кооперации позволяют приобрести разнообразные ресурсы, в литературе представлено недостаточное количество эмпирических исследований, подтверждающих значимость влияния факторов кооперации на результаты деятельности участников таких взаимодействий, а также на способности к нововведениям и инновационный потенциал фирмы [Sunley, 2003; Марков и Ягольницер, 2007; Hoffe and Chen, 2006].

В данном исследовании, используя методы эконометрического анализа, мы попытаемся оценить влияние факторов кооперации на показатели эффективности функционирования предприятий Пермского края.

Логика работы нашла свое отражение в структуре статьи. В следующем разделе будет представлен краткий обзор исследований, посвященных анализу взаимосвязи признаков кооперации и показателей результатов деятельности фирмы, на основании которых будет сформулирована тестируемая гипотеза. Следующий за ним раздел будет посвящен описанию используемых данных, а также вопросам построения моделей и их эконометрической оценке. Последний раздел работы представляет собой описание эмпирических результатов и выводов относительно мотивов кооперации, а также задач для дальнейшей работы.

\section{Взаимосвязь кооперации и результатов деятельности компаний: анализ эмпирических исследований}

Почему некоторые фирмы вступают в альянсы или кластеры? Существуют ли эффекты от кооперации? Анализ показывает, что в имеющихся исследованиях данные вопросы действительно актуальны. При этом нет однозначного подхода как к методам анализа, так и к индикаторам «успешности» взаимодействия, что, скорее всего, связано с различиями в доступе к информации и пока незрелой стадией исследований этой темы.

Так, анализ данных, полученных в ходе выборочного экспертного опроса предприятий Великобритании в 1997 г. практически всех секторов экономики с численностью работников более 10 человек стал одним из первых эмпирических исследований подобного рода в Европе. На основе методов эконометрического анализа (логистической регрессионной модели) авторы статистически протестировали связь между размером фирмы и вероятностью участия в кооперации, обнаружив устойчивые положительные оценки, не зависящие от отраслевой принадлежности. Помимо этого авторы доказали важность неформальных каналов коммуникации и источников знаний для инновационной деятельности, измеряемой объемом выучки от реализации инновационной продукции. Интересным является статистически значимое негативное влияние иностранных собственников, особенно для малых фирм. При этом полученные результаты отличаются в разрезе размерных групп: для малых предприятий, в отличие от крупных и средних, участие в кооперации имеет негативный эффект [Torbett, 2001].

Противоположный вывод был сделан в работе по исследованию эффектов от межфирменного трансферта знаний внутри стратегических альянсов на технологические 
возможности фирмы. Авторы на основе инструментария регрессионного анализа и выборки из 500 компаний-производителей полупроводников использовали образцы цитирования (citation patterns) на патенты участников взаимодействия. В качестве результирующего индикатора - изменение суммы затрат на НИОКР или количество вновь зарегистрированных патентов. Результаты демонстрируют, что молодые и малые фирмы получают больше выгод от участия в крупных инновационных альянсах в сравнении с крупными и «старыми» компаниями. Авторы делают выводы о том, что для организаций с большим количеством инновационно активных партнеров по альянсам темпы роста продаж и доля инновационной продукции выше, чем для сравнимых фирм с отсутствием таких партнеров [Stuart, 2000].

При этом выявленные связи необязательно носят линейный характер. Как показано в ряде работ [Nahapiet and Ghoshal, 1998; Hollenstein, 2001], взаимосвязь между разнообразием знаний, интенсивностью коммуникаций (в том числе неформальных), а также созданием знаний (или изобретательством) имеет обратную U-зависимость:

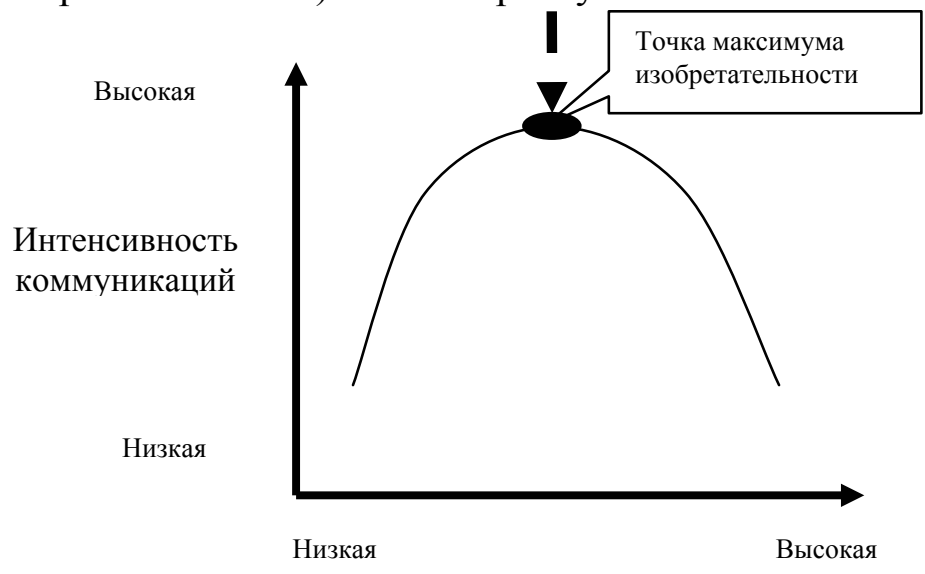

Степень

диверсификация знаний

Рисунок 1. Кривая изобретательности*

*Источник: [Hollenstein, 2001]

Полученные выводы акцентируют внимание на важности социального капитала, взаимного доверия, личного опыта, долгосрочности взаимодействия в процессе межфирменной кооперации [Porter, 2002; Saxenian, 1994]. Это также подтверждается результатами эмпирического исследования механизмов сотрудничества европейских компаний (рис.2): 


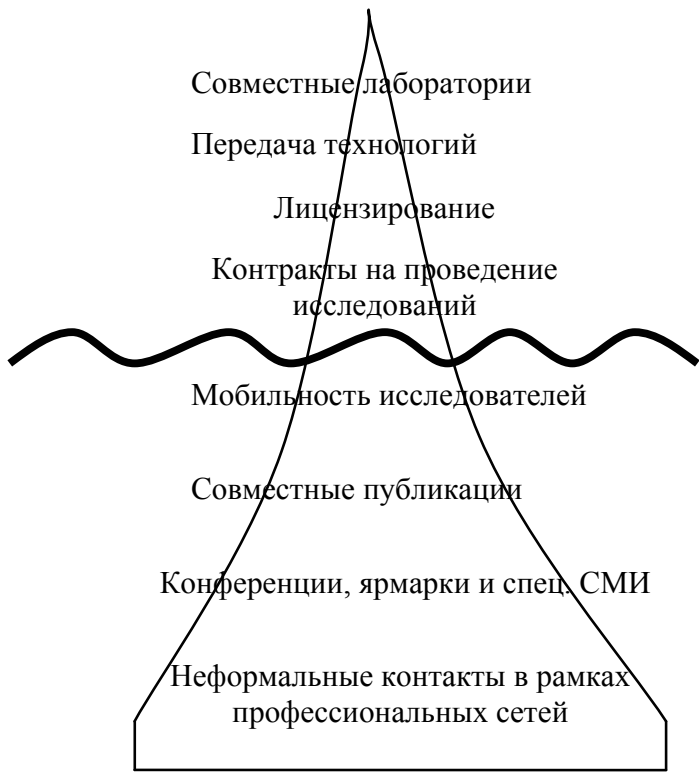

Рисунок 2. Формальные механизмы сотрудничества: вершина айсберга* *Источник: OECD, 2008

Кроме этого, сотрудниками исследовательского центра MERIT в университете Лимбурга (Голландия) было обнаружено, что более четверти всех межфирменных соглашений о сотрудничестве включают совместное проведение научных исследований [Maillat, 1998]. В результате сделаны выводы о том, что в сфере высоких технологий (особенно!) стимулы к подобному сотрудничеству не только сильны, но и способны к «самоусилению» за счет «постоянного взаимного обучения».

Еще один пласт исследований - анализ кластерных эффектов или оценка влияния участия в кластере на эффективность и инновационность фирм. При этом, как в случае с анализом стратегических альянсов, отличаются не только используемые методы, уровень микро- или макроанализа, но и получаемые результаты и выводы.

Например, результаты анализа поведения предприятий Европы на основе экспертного опроса, проведенных в рамках проекта Innobarometer в 2004 и 2006 гг., показали, что участие в кластере положительным образом взаимосвязано с основными индикаторами результатов инновационной деятельности фирм. Так, 78 и 63\% компаний, работающих в кластере, создали и внедрили новые или усовершенствованные продукты и технологии (по сравнению с 74 и 56\% двумя годами ранее соответственно). Такие результаты, по мнению авторов, показывают что «инновации действительно множатся в кластерах». Анализ других показателей эффективности функционирования компаний, таких как количество зарегистрированных патентов или торговых марок, демонстрирует схожие результаты. Тем не менее к результатам данной работы необходимо относиться с определенной долей осторожности: к объектам наблюдения в 2004 г. относились фирмы, занимающиеся инновациями, а в 2006 г. - фирмы-инноваторы и участники кластера одновременно [OECD, 2004, 2006].

Статистическое исследование европейских кластеров ${ }^{52}$ является одним из наиболее проработанных с точки зрения методики с использованием данных микроуровня. На первом этапе фирмы были разделены на относительно однородные группы в соответствии с

52 Результаты представленной работы базируются на данных Инновационного исследования Швеции, как части Инновационного исследования Европы (CIS 2). В течение 1997-1999 гг. были опрошены предприятия 28 отраслей, в каждой из которых были выделены три группы размерности по численности сотрудников. Анкета включала в себя широкий круг вопросов относительно инновационной активности, инновационного процесса, экономической деятельности. Исследование, проведенное в Швеции, включает в себя подвыборку из 2731 объектов наблюдения из 9 отраслей [Arvanitis and Hollenstein, 2001]. 
позицией в сети знаний - детерминантами спроса и предложения на инновационную продукцию, а также некоторыми структурными характеристиками фирмы, такими как размер, возраст, отрасль и т.д. С применением методов неиерархического кластерного анализа были идентифицированы четыре кластера, описанные в терминах «входящих» и «исходящих» индикаторов, охватывающих все стадии инновационного процесса. Среди входящих показателей были использованы: затраты на НИОКР, затраты на ИТ-технологии и объем связанных с инновациями инвестиций (инновационное оборудование, приобретенные внешние знания в виде лицензий, торговых марок, инвестиции в человеческий капитал, издержки на маркетинг). В качестве исходящих - доля инновационных продуктов в выручке фирмы, сумма снижения издержек, улучшение позиции на рынке, а также самооценка фирмы. Среди основных результатов можно выделить следующие:

- Производительность труда по добавленной стоимости положительно взаимосвязана с инновационными отраслями и негативно - с розничной торговлей и гостиничноресторанным бизнесом. Положительная связь была обнаружена для предприятий, принадлежащих к ИТ-кластеру, тесно связанному с процессами кооперации.

- Влияние на темпы роста выручки отрицательно связано с участием в ИТ-кластере и положительно - с кластером процессных инноваций с устойчивыми внешними связями в цепочке добавленной стоимости. Также для некоторых спецификаций модели было обнаружено статистически значимое влияние на зависимую переменную интенсивности использования капитала знаний (knowledge capital intensity) [Arvanitis and Hollenstein, 2001].

Ж. Симонен и Ф. Макканн, изучая эффект сообучения в работе предприятий Финляндии, основываются на статистике о кооперационной деятельности в сфере НИОКР (face-to-face contacts) и информации о межотраслевых потоках трудовых ресурсов, собранной в период с 1996-го по 2002 г. государственными статистическими органами [McCann and Simonen, 2008]. Результаты исследования позволили сделать следующие выводы: кооперация в сфере НИОКР обязательно требует наличия и дальнейшего усиления роли личных неформальных контактов, интенсивность которых ассоциируется с географической близостью. Авторы исследования делают вывод: таким образом, процессы кооперации в пределах кластера и инновационная активность его участников положительно взаимосвязанные процессы. А предприятия, составляющие инновационное ядро кластера, характеризуются разнообразием внешних связей.

В исследовании итальянских ученых [Maggioni and Riggi, 2006], авторы на отраслевом уровне выделили 1224 высокотехнологичных кластера на основе данных шести высокотехнологичных отраслей всех штатов США за период с 1988-го по 2003 г. Каждый инновационный кластер был определен по трем координатам: штат, отрасль, год (всего 1224 наблюдения) в соответствии с критерием численности жителей штата, при условии статистической значимости в регрессионном анализе его влияния на концентрацию отраслей. Дальнейший эконометрический анализ показал, что характеристики отрасли для выделенных кластеров превалируют над характеристиками штата на протяжении всего исследуемого периода. Авторы делают достаточно любопытные выводы. Рост производительности труда объясняется не принадлежностью к тому или иному высокотехнологичному кластеру, а жизненным циклом самой отрасли. По мнению авторов, более «молодые» отрасли имеют тенденцию к большей концентрации в пределах штата, даже если они не являются участниками кластера. Тем не менее взаимодействие между схожими отраслями и предприятиями внутри штата оказалось положительно связано с ростом производительности.

М. Бенгстон и др. [Bengtsson and Solvell, 2004] на основе эконометрического анализа анкет 144 предприятий разного размера и отраслей шведской промышленности подтвердили гипотезу о положительной роли кооперационных связей с поставщиками и потребителями внутри кластера на инновационную активность с преобладанием вертикальной кооперации в отраслях с высокой степенью конкуренции. 
В целом, за некоторым исключением [Madhavan, Koka and Prescott, 1998], эмпирические исследования стратегических альянсов, сетей и кластеров в основном связаны с кросс-секционных анализом с использованием методов эконометрического анализа, а также качественных case-studies и success stories.

Подводя итог анализа теоретических и эмпирических исследований, можно сделать вывод о том, что возрастающее количество работ в области анализа межфирменного взаимодействия обозначает важность потенциала кооперации. При этом попытки связать этот потенциал с конкурентоспособностью фирмы, осуществляемые в основном на уровне экспертных опросов, имеют достаточно ограниченные и неочевидные результаты для исследователей и практиков. Такой подход не позволяет точно фокусировать региональную политику, обеспечивать ее эффективность и ориентацию на те объекты, которые действительно могут активно воздействовать на конкурентоспособность бизнеса и способствовать развитию региона. Это и определяет теоретическую и практическую значимость исследования.

\section{Методология эмпирического исследования}

Целью нашего эмпирического исследования является анализ влияния факторов кооперации на показатели результатов функционирования предприятий. Количественная оценка проведена на основе инструментария корреляционного и регрессионного анализа с применением программного пакета SPSS 11.0.

Исследуемый массив сформирован на основе данных о 401 предприятии различных видов деятельности Пермского края за 2005 и 2007 гг. ${ }^{53}$.

Серьезным ограничением при принятии решения о включении предприятия в выборку было отсутствие у предприятия статистических индикаторов. База данных включает в себя информацию, полученную по запросам от Территориального органа Федеральной службы государственной статистики по Пермскому краю и Министерства торговли и развития предпринимательства Пермского края с пообъектным присоединением отдельных индикаторов баз данных бухгалтерской отчетности «FIRA PRO» и «СПАРК-ИНТЕРФАКС». С использованием, кроме этого, традиционных источников информации - сайтов компаний в сети Интернет, публикаций в прессе, доступных данных Федеральной службы государственной статистики, Министерств и ведомств Пермского края и Российской Федерации.

Распределение компаний по отраслям представлено на риснке 3 , а также в таблице 1 Приложения. Несмотря на смещенность выборки в сторону обрабатывающих отраслей, анализ репрезентативности показал, что выборка соответствует структуре экономики Пермского края (по доле количества предприятий отрасли в выборке и генеральной совокупности), являясь репрезентативной в целом и в разрезе отдельных видов деятельности.

\footnotetext{
${ }^{53}$ Необходимо отметить, что в силу отсутствия определенных данных, в частности, о структуре себестоимости, у ряда объектов наблюдений, рассчитать некоторые показатели, такие как, например, добавленная стоимость, оказалось невозможно. Эти объекты наблюдения квалифицировались как пропуски (missings) и автоматически исключались из корреляционного и регрессионного анализа.
} 


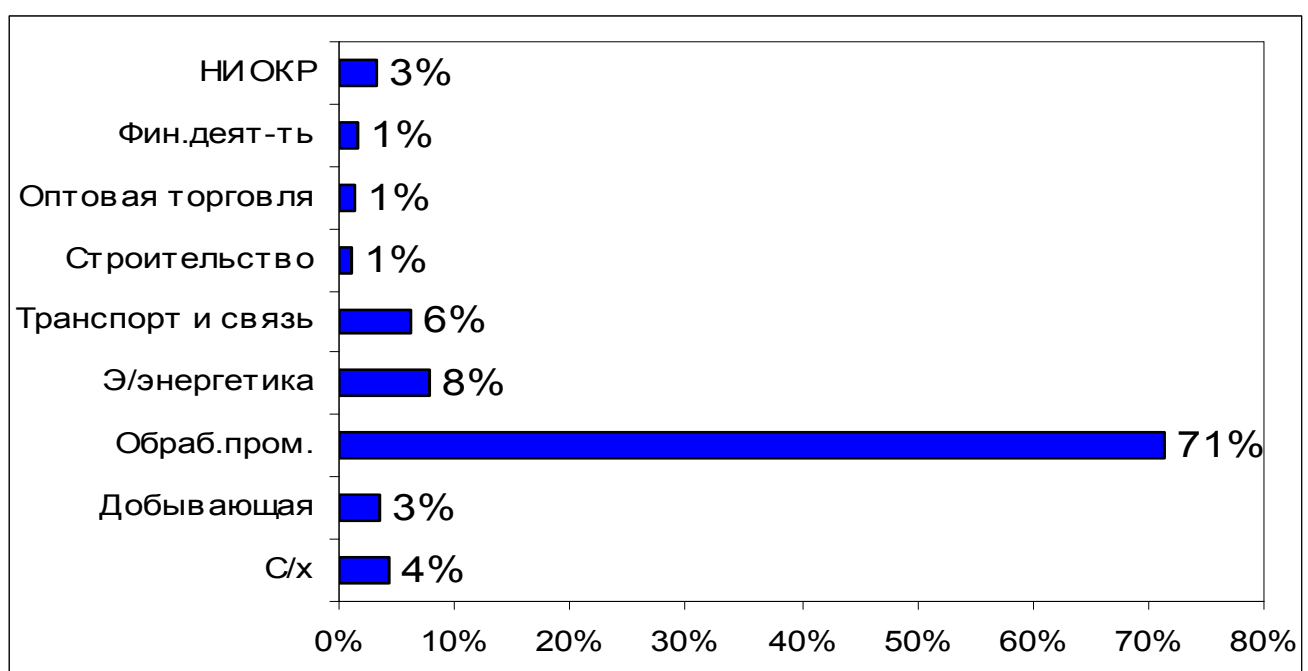

Рисунок 3. Распределение объектов наблюдения выборочной совокупности в разрезе укрупненных ОКВЭДов

Массив данных включает в себя информацию по показателям, описывающим:

- общие характеристики: форму и структуру собственности, возраст фирмы, отраслевую принадлежность;

- финансовые показатели: выручку, структуру себестоимости, рентабельность продаж, удельные трудовые издержки (по добавленной стоимости, по выручке);

- специфичные, необходимые для целей исследования, индикаторы: производительность труда по валовой добавленной стоимости, экспорт (факт), расходы на НИОКР (факт), совместные инновационные проекты, отраслевые ассоциации, коэффициенты специализации и локализации и др.

Некоторые из них представлены в таблице 2. 
Описательные статистики (по данным 2007 г.)

\begin{tabular}{|l|c|c|c|c|c|c|}
\hline \multicolumn{1}{|c|}{ Показатель } & $\begin{array}{c}\text { Кол-во } \\
\text { объектов } \\
\text { наблюдения }\end{array}$ & Минимум & Максимум & Ср. знач. & Медиана & $\begin{array}{c}\text { Станд. } \\
\text { откл. }\end{array}$ \\
\hline $\begin{array}{l}\text { Производительность } \\
\text { труда по ВДС, тыс.руб. }\end{array}$ & 374 & $-264,29$ & 15447,83 & 599,26 & 300,78 & 1418,26 \\
\hline Возраст фирмы, лет & 401 & 2 & 27 & 9,7 & 10,00 & 4,6 \\
\hline $\begin{array}{l}\text { Рентабельность продаж, } \\
\%\end{array}$ & 398 & $-1,66$ & 1,00 &, 13 &, 13 &, 25 \\
\hline $\begin{array}{l}\text { Количество } \\
\text { работников, чел. }\end{array}$ & 397 & 2 & 15527 & 704 & 164,00 & 1632 \\
\hline $\begin{array}{l}\text { Количество фирм той } \\
\text { же отрасли в городе, ед. }\end{array}$ & 385 & 0 & 826 & 21,75 & 7,00 & 66,041 \\
\hline $\begin{array}{l}\text { Удельные трудовые } \\
\text { издержки (по ВДС), } \\
\text { тыс. руб. }\end{array}$ & 379 & $-30,03$ & 44,00 &, 55 &, 52 & 2,91 \\
\hline $\begin{array}{l}\text { Отклонение } \\
\text { производительности } \\
\text { труда по ВДС от } \\
\text { лучшей по отрасли в } \\
\text { выборке, тыс. руб. }\end{array}$ & 382 & $-15290,51$ & 15450,66 & 1997,22 & 1184,06 & 3099,18 \\
\hline
\end{tabular}

Тестируемая в данном исследовании гипотеза предполагает, что при прочих равных условиях признаки кооперации положительно влияют на показатели результатов функционирования фирм. Среди внутренних и внешних факторов межфирменного взаимодействия мы ожидаем значимых коэффициентов при следующих показателях:

- участии предприятия в региональных отраслевых и других бизнес-ассоциациях, что связано с ожиданиями влияния «тусовок» - неформального обмена информацией о технологиях, продуктах и т.д.;

- совместные проекты в сфере НИОКР; в частности, мы предполагаем, что инновации, создаваемые посредством различных форм и механизмов межфирменного сотрудничества, положительным образом влияют на показатели результатов фирм;

- включенность фирмы в глобальную конкуренцию, которая требует поддержания постоянного уровня инновационной активности и выражается в наличии экспорта;

- нахождение в пределах агломерации, что связано с наличием и доступностью необходимой инфраструктуры, «тусовки» для общения или свойствами «жирного рынка» [Российская промышленность, 2008];

- инновационность предприятий в целом, проявляющаяся в наличии расходов на НИОКР и инвестициях в основной капитал; при этом мы полагаем, что с учетом специфики экономики Пермского края такие процессы характерны скорее для крупных, нежели малых и средних компаний.

Для поверки сформулированных предположений по данным 2007 г. были построены линейные многофакторные модели следующего вида:

$$
Y=\alpha_{0}+\alpha_{1} \text { Firm }+\alpha_{2} R \& D+\alpha_{3} \text { Ind }+\alpha_{4} \text { Aglm }+\alpha_{5} \text { Assoc }+\xi,
$$

где $\alpha_{0}$ - константа, $\xi$ - случайная ошибка, $Y$ - зависимая переменная, определяющая итоги деятельности фирмы. Были рассмотрены модели со следующими результирующими признаками:

- рентабельность продаж (PR_TR);

- объем выручки на одного работника (TR_Empl);

- производительность труда по валовой добавленной стоимости (TP_AdV). 
В качестве объясняющих переменных были использованы индикаторы, характеризующие различные аспекты межфирменного взаимодействия:

Firm - индивидуальные свойства предприятия, отражающие его финансовохозяйственную деятельность: (1) переменная, характеризующая инвестиции в основной капитал (Сарех); (2) дихотомическая переменная, характеризующая интеграцию фирмы в глобальные рынки и принимающая значение 1 , если предприятие является экспортером, 0 в противном случае (Ехр);

$R \& D$ - индивидуальные свойства предприятия, отражающие его инновационную деятельность: (1) дихотомическая переменная, принимающая значение 1, если в 2007 г. предприятие осуществляло затраты на НИОКР, 0 - в противном случае (R\&Dexp); дихотомическая переменная, принимающая значение 1 , если предприятие имело совместные проекты с внешними источниками знаний, 0 - в противном случае (Соop);

$\mathrm{Aglm}$ - дихотомическая переменная, принимающая значение 1, если предприятие расположено в пределах городской агломерации, 0 - во всех остальных случаях ${ }^{54}$;

Ind - свойства отрасли, в которой функционируют предприятия: показатель количества фирм аналогичной отрасли (в разрезе четырехзначного ОКВЭДа) по адресу (поселение) нахождения предприятия (Firm_q);

Assoc - дихотомическая переменная, принимающая значение 1, если предприятие относится к участникам бизнес-ассоциаций, 0 - в противном случае.

Обозначенные факторы были выбраны исходя из результатов предыдущих эмпирических и теоретических исследований в области изучения открытых инноваций.

Необходимо отметить, что многие из перечисленных выше факторов могут влиять одновременно на зависимую и независимые переменные. Для устранения этого эффекта мы ввели в модель контрольные переменные размера и принадлежности к отрасли предприятия: среднесписочную численность работников в 2007 г. (Empl) и дихотомический показатель, принимающий значение 1 , если предприятие относится к химической отрасли, 0 - во всех других случаях (Chem_Ind).

Модель исследования содержит как очевидные факторы, характеризующие индикаторы межфирменной кооперации, так и факторы, которые могут косвенно свидетельствовать о взаимодействии фирм в сфере НИОКР. При описании результатов исследования влияние наиболее значимых факторов будет проинтерпретировано.

Bсе независимые переменные во всех моделях были предварительно проверены на мультиколлинеарность. Результаты анализа на основе коэффициентов корреляции Пирсона для интервальных переменных, а также процедуры Crosstabs и коэффициента эта (Eta) для бинарных переменных предварительно демонстрируют ожидаемые результаты. В частности, существует положительная и статистически значимая связь между производительностью труда по ВДС и наличием у предприятия затрат на НИОКР, инвестициями в основной капитал, наличием экспорта. Также существует положительная связь между рентабельностью продаж и наличием у предприятия совместных инновационных проектов с внешними источниками знаний, а кроме того, участием в Ассоциациях (см. табл. 2 и 3 Приложения).

Результаты оценок линейных регрессионных моделей приведены в таблице 4 (Приложение). Уравнения оцененных функций регрессий имеют вид:

- TR_Empl $=1654,640 \mathrm{Assoc}+$ 0,002Capex + 911,218Export $-0,396 \mathrm{Empl}$;

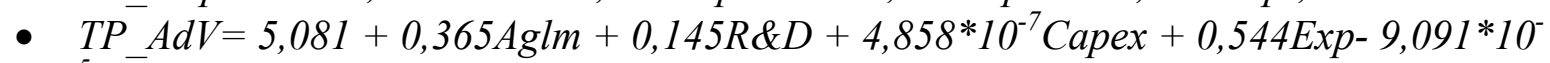
${ }^{5} \mathrm{Empl}$;

- $P r_{-} T R=0,080 \mathrm{Aglm}+2,165 * 10^{-5} \mathrm{Empl}$.

54 В соответствии с информацией Министерства экономического развития Пермского края, в регионе выделены три городские агломерации с удаленностью от центра агломерации не более чем на 50 км: 1) города Пермь, Краснокамск, поселок Полазна, Краснокамский и Пермский районы; 2) города Березники, Соликамск и Соликамский район; 3) города Лысьва, Чусовой, Кунгур. 
На основе значения F-статистики мы можем сделать вывод о статистической значимости каждой модели на уровне $1 \%$. Тем не менее, результаты анализа говорят в целом о слабой корреляции между зависимыми и независимыми переменными.

В первой модели была обнаружена положительная взаимосвязь между удельной выручкой и участием в региональных бизнес-ассоциациях, инвестициями в основной капитал, а также наличием экспорта; при этом оказалось, что численность работников оказывает отрицательное воздействие.

В отличие от первой модели, среди факторов, влияющих на производительность труда по валовой добавленной стоимости, показали свою значимость такие внешние и внутренние индикаторы, как нахождение в пределах городской агломерации и наличие расходов на НИОКР соответственно.

Результаты второй модели, помимо положительного влияния факта нахождения в пределах городских агломераций, демонстрируют противоположный результат воздействия численности работников на рентабельность продаж.

В целом полученные результаты совпадают с нашими предположениями, однако следует отдельно охарактеризовать выводы, полученные по ряду факторов.

Оценки построенных регрессий, а также количество фирм конкурентов-партнеров по кооперации и индикаторами результатов свидетельствуют об отсутствии значимой зависимости между участием в совместных инновационных проектах. Полученные результаты не согласуются с выводами зарубежных эмпирических исследований. Так, при изучении европейских кластеров [OECD, 2006] выяснилось, что более $25 \%$ фирм, находящихся в границах кластера, работают в тесной кооперации с другими местными фирмами, а $36 \%$ активно сотрудничают с лабораториями и государственными научными центрами. Однако, как отмечено в Малмбергом и Пауэром [Malmberg and Power, 2006], существующие эмпирические свидетельства не позволяют считать «этот путь единственным эффективным механизмом генерации новых знаний». Полученный результат может интерпретироваться как превалирование неформальных взаимодействий, оцениваемых через участие в бизнес-ассоциациях, над формальными контактами, что поддается логическому объяснению и отражено в зарубежных и российских эмпирических работах.

Многие исследователи связывают высокий уровень затрат на НИОКР и технологическую сложность продукции с высоким уровнем кооперации. Кооперация (в том числе и с университетами) выше у компаний с более высоким уровнем расходов на НИОКР и уровнем патентной активности [Freeman, 1995; Hagedorn, 2002; Maggioni and Riggi, 2006]. То есть предприятия, обладающие технологической базой и осуществляющие НИОКР, рассматриваются как наиболее привлекательные партнеры для кооперации.

Кроме этого, на наш взгляд, важным представляется вывод о том, что характер кооперации (в данном случае с поставщиками) между предприятиями в Пермском крае носит в основном инвестиционный характер, а не характер практик открытых инноваций ${ }^{55}$, а также ассоциируется с экспортной активностью. Последний вывод говорит о том, что действительно предприятия, сталкивающиеся с глобальной конкуренцией, вынуждены проявлять большую инновационную активность, перенимая опыт зарубежных конкурентов и партнеров, сотрудничая с внешними источниками знаний не только внутри региона [Российская промышленность, 2008; Исакин, Теплых, 2009].

Расположение предприятия в границах городской агломерации демонстрирует вполне интерпретируемые результаты: именно «столичные территории» (metropolitan regions) имеют преимущество, так как характеризуются свойством разнообразия в выборе партнеров для кооперации в этих взаимодействиях. При этом географическая близость не обязательно оказывается необходимым и достаточным условием для взаимодействия, но вместе с тем действительно может облегчить кооперацию [Boschma and Weterings, 2005].

\footnotetext{
55 При этом необходимо помнить о том, что модернизация оборудования, тем не менее, относится к инновациям имитационного характера.
} 
Необходимо отметить, что результаты демонстрируют отсутствие влияния каких-либо специфических отраслевых свойств, а также статистическую значимость размера компании. Что касается последнего, то в зависимости от спецификации влияние этого фактора оказывалось разным - и положительным, и отрицательным. С одной стороны, результаты вполне объяснимы - как было показано ранее [Torbett, 2001; Stuart, 2000], в различных эмпирических исследованиях к участию в инновационных кооперационных практиках более мотивированы и крупные, и малые предприятия. С другой стороны, это может говорить о неустойчивости полученных оценок.

Таким образом, на данной выборке компаний в целом мы нашли подтверждение того, что существует взаимосвязь между процессами межфирменного взаимодействия и кооперации и показателями результатов компании, что в целом согласуется с результатами зарубежных эмпирических исследований. При этом нельзя не отметить как довольно слабую зависимость между анализируемыми зависимыми переменными и предикторами, так и статистическую незначимость «истинного» [Arita and McCann, 2000] показателя взаимодействия - совместных проектов в сфере НИОКР.

\section{Заключение}

Данная статья представляет собой описание результатов анализа процессов кооперации в сфере НИОКР, а также количественной оценки влияния различных факторов взаимодействия на индикаторы результатов фирм. В выборку были включены компании, зарегистрированные на территории Пермского края. Необходимо отметить, что исследование эффектов кооперации по данным микроуровня, с одной стороны, признается аналитиками в качестве одного из наиболее популярных подходов, с другой - остается не разработанным как с точки зрения теории и методики, так и критической массы эмпирических работ.

Построенные модели множественной линейной регрессии зависимого показателя результатов компании, измеряемого производительностью труда по валовой добавленной стоимости, рентабельностью продаж и удельной выручкой, включают ряд независимых факторов, характеризующих различные аспекты межфирменного взаимодействия в сфере НИОКР. В процессе исследования были получены следующие результаты:

- положительная взаимосвязь между индикаторами результатов и расположением компании в границах городских агломераций, инвестициями в основной капитал и наличием экспорта;

- слабая положительная взаимосвязь между производительностью труда и удельной выручкой и осуществлением затрат на НИОКР и участием в отраслевых и других бизнес-ассоциациях соответственно;

- разнонаправленное, в зависимости от спецификации модели, но устойчивое влияние размера компании на полученные результаты;

- отсутствие влияния отраслевых характеристик на анализируемые признаки.

Эти результаты не опровергли, а по ряду выводов подтвердили гипотезу о положительной взаимосвязи факторов кооперации между предприятиями и внешними источниками знаний в сфере НИОКР и финансовыми результатами деятельности фирм. Однако часть наших предположений в результате проведения эконометрического анализа данных не подтвердилась.

Подводя итог, необходимо отметить ряд недостатков описанного исследования. Вопервых, ограниченность официальных статистических индикаторов взаимодействия не позволила нам в полном объеме выполнить задуманное, поскольку статистические органы не собирают данные, например, о длительности совместных инновационных проектов для оценки устойчивости выбора партнеров по кооперации, что требует дополнительных экспертных опросов и качественных интервью. В-вторых, в наших моделях не всегда ясно, является ли данный индикатор признаком конкурентоспособности кластера или фактором, 
который эту конкурентоспособность определяет. Другими словами, четко не определены направления причинно-следственной связи, что означает необходимость проверки сделанных выводов на эндогенность, например, путем введения в анализ инструментальных переменных. Перечисленные недостатки дают нам возможность продолжить работу над исследованием в будущем. Соответственно анализ эндогенности поиска и добавление новых факторов в модели при наличии новых и альтернативных источников информации, а также качественных анализ-механизмов, стимулов и негативных эффектов кооперационных практик открывает возможности для дальнейшего исследования моделей долгосрочного стратегического развития компаний.

\section{Список использованной литературы}

1. Grant R. B. (1996), Towards a knowledge-based theory of the firm, Strategic Management Journal, 17 (1996) 109-122.

2. Teece D.J. (2000) Strategies for Managing Knowledge Assets: the Role of Firm Structure and Industrial Context, Long Range Planning, 33 (1) (2000) 35-54

3. Ahuja G. The Duality of Collaboration: Inducements and Opportunities in the Formation of Interfirm Linkages // Strategic Management Journal, Special Issue: Strategic Networks. Vol. 21. No. 3. 2000. P. 317-343 http://www.jstor.org/stable/3094190

4. Torbett R. (2001) Technological Collaboration, Firm size and Innovation: A study of UK Manufacturing Firms. Innovative networks: Co-operation in NIS. - OECD: OECD Proceedings, p. 77-101.

5. Raasch Ch., Herstatt C. and Lock Ph. (2008), The Dynamics of user Innovation: Drivers and Impediments of innovation Activities, International Journal of Innovation Management. Special Issue on User Innovation, 12(3) (2008) 377-398.

6. Chesbrough H. (2006). Open Innovation: A New Paradigm for Understanding Industrial Innovation. - Oxford: Oxford University Press.

7. Iammarino S., McCann $\mathrm{Ph}$. The Structure and Evolution of Industrial Clusters: Transactions, Technology and Knowledge Spillovers // Science and Technology Policy Research. Paper № 138. 2006. http://www.sussex.ac.uk./spru

8. Lundvall B. (1992). National Systems of Innovation: Towards a Theory of Innovation and Interactive Learning. - London: Pinter Publishers.

9. Audretsch D., Feldman M.P. (2003). Knowledge Spillovers and the Geography of Innovation in J. Vernon Henderson and Jacque Thisse, ed. Handbook of Urban and Regional Economics, Volume 4. Amsterdam: North Holland Publishing

10. Walker G., Kogut B., Shan W. Social capital, structural holes and the formation of an industry network. Organization Science. -1997. - 8(2), pp.109-125.

11. Hollenstein H. Innovation Modes in the Swiss Service Sector: A cluster analysis based on firm-level data. Innovative networks: Co-operation in NIS. - OECD: OECD Proceedings, p. 77-101

12. McKendrick D. (2001), Global strategy and population-level learning: the case of hard disk drives, Strategic Management Journal, 22(4) (2001) 307-334.

13. Saxenian, A. (1994). Regional Advantage: Culture and Competition in Silicon Valley and Route 128. - Cambridge: Harvard University Press.

14. Cipolla J.H., Cavalcanti M. and de Castro Souza R. (2006). Co-opetition: Cooperation and Competition, Knowledge, Innovation and Competitiveness: Dynamics of Firms, Networks, Regions and Institutions.- Copenhagen: DRUID Summer conference.

15. Sunley M.R. (2003), Deconstructing clusters: Chaotic concept or policy panacea?, Journal of Economic Geography, 3 (2003) 5-35

16. Марков Л.С., Ягольницер М.А. Исследование наукоемких предприятий Новосибирска. Кластерный подход. http://www.sibai.ru/index.php?option=com content\&task=view\&id $=506 \&$ Itemid $=620$ 
17. Hoffe R., Chen K. (2006), Whither or not industrial cluster: conclusions or confusions? // The Industrial Geographer, 4 (2006) 2-28.

18. Stuart T.E. Interorganizational Alliances and the Performance of Firms: A Study of Growth and Innovation Rates in a High-Technology Industry // Strategic Management Journal. Vol. 21. No. 8. 2000. P. 791-811. http://www.jstor.org/stable/3094397

19. Nahapiet J., Ghoshal S. (1998), Social Capital, Intellectual Capital, and the Organizational Advantage, Academy of Management Review, 23 (2) (1998) 242-266.

20. Porter M.E. (2002). National Innovative Capacity. Scott S., Porter M.E. (eds). Washington (DC): Council on Competitiveness.

21. Empirical Measures of Open Innovations. (2008). Open innovations in Global Networks. OCED: OECD Proceedings, p. 49-74.

22. Maillat D. (1998), From the industrial district to the innovative milieu: Contribution to an analysis of territorialized productive organizations, Research Economiques de Louvain, 64 (1) (1998).

23. Innobarometr on cluster's role in facilitating innovation // Analytical report. 2004, 2006. http://cordis.europa.eu/innovation/en/policy/innobarometer.htm

24. Arvanitis S. , Hollenstein H. (2001). Innovative Activity and Firm Characteristics: A cluster analysis of Swiss manufacturing using firm-level. Innovative networks: Cooperation in NIS. - OECD: OECD Proceedings, p. 49-76.

25. McCann Ph., Simonen. (2008), The Influence of R\&D Cooperation and the Geography of Human Capital Inputs, Journal of Urban Economics, 64 (1) (2008) 146-154

26. Maggioni M., Riggi M. (2006), High-Tech Firms and the Dynamics of Innovative Industrial Clusters, Knowledge, Innovation and Competitiveness: Dynamics of Firms, Networks, Regions and Institutions, 2006.

27. Bengtsson M., Solvell Ö. (2004), Climate of competition, clusters and innovative performance, Scandinavian Journal of Management, 20 (2004) 225-244.

28. Madhavan R., Koka B. R. and Prescott J. E. (1998), Networks in transition: How industry events (re)shape interfirm relationships, Strategic Management Journal, 19(5) (1998) 439459.

29. Российская промышленность на этапе роста: факторы конкурентоспособности фирм / Под редакцией К. Р. Гончар и Б. В. Кузнецова- М.: Вершина, 2008.

30. Innovation Clusters in Europe: A statistical analysis and overview of current policy support // DG Enterprise and industry report. 2006. http://innovating regions.org/templates/ris doc counter.cfm?doc $\mathrm{id}=3742 \&$ doc type $=\mathrm{doc}$

31. Malmberg A., Power D. (2006). True Clusters. A Severe Case of Conceptual Headache, in Asheim, Cooke and Martin (eds.) Clusters in Regional Development, Regional Development and Public Policy Series. Routledge: London, 2006, p.6-34

32. Freeman C. (1995), The National System of Innovation in Historical Perspective // Cambridge Journal of Economics, 19 (1) (1995) 345-377.

33. Hagedoorn, J. (2002), Inter-firm R\&D Partnerships: An Overview of Major Trends and Patterns since 1960, Research Policy, 31(3) (2002) 477-492.

34. Исакин М.А., Теплых Г.В. (2008), Условия развития кластеров в экономической системе Пермского края // Региональная экономика: теория и практика. 2009. №24. C.27-34.

35. Boschma R., Weterings A. The effect of regional differences on the performance of software firms in Netherlands // Papers in Evolutionary Economic Geography. 2005. http://econ.geog.uu.nl/peeg/peeg.html 


\section{Приложение}

Таблица 1

Распределение предприятий в выборочной совокупности по видам экономической деятельности (по данным о количестве предприятий Пермского края)*

\begin{tabular}{|c|c|c|c|}
\hline № & ОКВЭД & $\begin{array}{c}\text { Число } \\
\text { предприятий, } \\
\text { ед. } \\
\end{array}$ & $\begin{array}{c}\text { Доля предприятий } \\
\text { отрасли в выборке, \% }\end{array}$ \\
\hline 1 & $\begin{array}{l}\text { C/х, охота и предоставление услуг в } \\
\text { этих областях }\end{array}$ & 17 & 4,24 \\
\hline 2 & $\begin{array}{l}\text { Добыча топливно-энергетических } \\
\text { полезных ископаемых }\end{array}$ & 6 & 1,50 \\
\hline 3 & $\begin{array}{l}\text { Добыча полезных ископаемых, кроме } \\
\text { топливно-энергетических }\end{array}$ & 8 & 2,00 \\
\hline 4 & $\begin{array}{l}\text { Производство пищевых продуктов, } \\
\text { включая напитки, и табака }\end{array}$ & 40 & 9,98 \\
\hline 5 & Текстильное и швейное производство & 3 & 0,75 \\
\hline 6 & $\begin{array}{l}\text { Обработка древесины и производство } \\
\text { изделий из дерева }\end{array}$ & 10 & 2,49 \\
\hline 7 & $\begin{array}{l}\text { Бумажное производство; издательская и } \\
\text { полиграфическая промышленность }\end{array}$ & 12 & 2,99 \\
\hline 8 & $\begin{array}{l}\text { Производство кокса, нефтепродуктов и } \\
\text { ядерных материалов }\end{array}$ & 6 & 1,50 \\
\hline 9 & Химическое производство & 44 & 10,47 \\
\hline 10 & $\begin{array}{l}\text { Производство резиновых и } \\
\text { пластмассовых изделий }\end{array}$ & 12 & 2,99 \\
\hline 11 & $\begin{array}{l}\text { Производство прочих неметаллических } \\
\text { минеральных продуктов }\end{array}$ & 3 & 0,75 \\
\hline 12 & $\begin{array}{l}\text { Металлургическое производство и } \\
\text { производство готовых металлургических } \\
\text { изделий }\end{array}$ & 48 & 11,97 \\
\hline 13 & Производство машин и оборудования & 59 & 14,71 \\
\hline 14 & $\begin{array}{l}\text { Производство электрооборудования, } \\
\text { электронного и оптического } \\
\text { оборудования }\end{array}$ & 24 & 5,99 \\
\hline 15 & $\begin{array}{l}\text { Производство транспортных средств и } \\
\text { оборудования }\end{array}$ & 10 & 2,49 \\
\hline 16 & Прочие производства & 17 & 4,24 \\
\hline 17 & $\begin{array}{l}\text { Производство и распределение } \\
\text { электроэнергии, газа и воды }\end{array}$ & 29 & 7,23 \\
\hline 18 & Строительство & 4 & 1,00 \\
\hline 19 & $\begin{array}{l}\text { Оптовая торговля, включая торговлю } \\
\text { через агентов, кроме торговли } \\
\text { автотранспортными средствами и } \\
\text { мотоциклами }\end{array}$ & 5 & 1,25 \\
\hline 20 & Транспорт и связь & 25 & 6,23 \\
\hline 21 & Финансовая деятельность & 6 & 1,50 \\
\hline 22 & Научные исследования и разработки & 13 & 3,24 \\
\hline \multicolumn{2}{|r|}{$\begin{aligned}- \text { Всего }\end{aligned}$} & 401 & 100 \\
\hline
\end{tabular}


* Расчеты автора на основе данных Управления федеральной службы статистики по Пермскому краю

Таблица 2

Коэффициенты парных корреляций между переменными (интервальными) тестируемых моделей

\begin{tabular}{|c|c|c|c|c|c|c|c|c|}
\hline & Показатель & & 1 & 2 & 3 & 4 & 5 & 6 \\
\hline \multirow{3}{*}{1} & \multirow{3}{*}{$\begin{array}{c}\text { Производительность } \\
\text { труда по ВДС }\end{array}$} & $\begin{array}{l}\text { Коэф. } \\
\text { корреляции }\end{array}$ & 1 & & & & & \\
\hline & & Значимость & . & & & & & \\
\hline & & $\begin{array}{l}\text { Кол-во } \\
\text { объектов } \\
\text { набл. }\end{array}$ & 374 & & & & & \\
\hline \multirow{3}{*}{2} & \multirow{3}{*}{$\begin{array}{c}\text { Выручка на одного } \\
\text { работника }\end{array}$} & $\begin{array}{l}\text { Коэф. } \\
\text { корреляции }\end{array}$ & ,730 & 1 & & & & \\
\hline & & Значимость & ,000 & . & & & & \\
\hline & & $\begin{array}{l}\text { Кол-во } \\
\text { объектов } \\
\text { набл. }\end{array}$ & 372 & 395 & & & & \\
\hline \multirow{3}{*}{3} & \multirow{3}{*}{$\begin{array}{c}\text { Рентабельность } \\
\text { продаж }\end{array}$} & $\begin{array}{l}\text { Коэф. } \\
\text { корреляции }\end{array}$ & ,207 &, 112 & 1 & & & \\
\hline & & Значимость & , 000 & , 027 & . & & & \\
\hline & & $\begin{array}{l}\text { Кол-во } \\
\text { объектов } \\
\text { набл. } \\
\end{array}$ & 371 & 392 & 398 & & & \\
\hline \multirow{3}{*}{4} & \multirow{3}{*}{$\begin{array}{c}\text { Инвестиции в } \\
\text { основной капитал }\end{array}$} & $\begin{array}{l}\text { Коэф. } \\
\text { корреляции }\end{array}$ &, $412(* * *)$ &, $309(* * *)$ &, $133(* *)$ & 1 & & \\
\hline & & Значимость & ,000 & ,000 & ,008 & . & & \\
\hline & & $\begin{array}{l}\text { Кол-во } \\
\text { объектов } \\
\text { набл. } \\
\end{array}$ & 374 & 395 & 397 & 400 & & \\
\hline \multirow{3}{*}{5} & \multirow{3}{*}{$\begin{array}{c}\text { Кол-во фирм } \\
\text { отрасли в поселении }\end{array}$} & $\begin{array}{l}\text { Коэф. } \\
\text { корреляции }\end{array}$ &, 033 & 017 &, 032 &,- 008 & 1 & \\
\hline & & Значимость & ,538 & ,742 &, 534 & ,873 & . & \\
\hline & & $\begin{array}{l}\text { Кол-во } \\
\text { объектов } \\
\text { набл. }\end{array}$ & 361 & 379 & 382 & 384 & 385 & \\
\hline \multirow{3}{*}{6} & \multirow{3}{*}{$\begin{array}{c}\text { Среднесписочная } \\
\text { численность } \\
\text { работников }\end{array}$} & $\begin{array}{l}\text { Коэф. } \\
\text { корреляции }\end{array}$ &, $100(*)$ & ,097 (*) &, $225(* * *)$ &, $524(* * *)$ &,- 037 & 1 \\
\hline & & Значимость &, 053 &, 054 & ,000 &, 000 &, 474 & . \\
\hline & & $\begin{array}{l}\text { Кол-во } \\
\text { объектов } \\
\text { набл. } \\
\end{array}$ & 374 & 395 & 394 & 397 & 381 & 397 \\
\hline
\end{tabular}

Для оценки использован коэффициент корреляции Пирсона. Корреляция статистически значима: *** на уровне $1 \%$, ** на уровне $5 \%$, * на уровне $10 \%$ 
Результаты оценки коэффициентов связи. Эта межу переменными (номинальными и интервальными) тестируемых переменных

\begin{tabular}{|c|c|c|c|c|c|c|c|c|c|c|c|c|c|c|c|}
\hline \multirow[b]{2}{*}{ Показатель } & \multicolumn{3}{|c|}{\begin{tabular}{|c|} 
Расположение в \\
пределах агломерации
\end{tabular}} & \multicolumn{3}{|c|}{ Участие в Ассоциациях } & \multicolumn{3}{|c|}{ Наличие затрат на НИОКР } & \multicolumn{3}{|c|}{ Наличие экспорта } & \multicolumn{3}{|c|}{\begin{tabular}{|c|} 
Участие в \\
совместных проектах
\end{tabular}} \\
\hline & Коэф. & \begin{tabular}{|l} 
Значим \\
ость
\end{tabular} & \begin{tabular}{|l|} 
Кол-во \\
объектов \\
набл.
\end{tabular} & Коэф. & \begin{tabular}{|l|l} 
Значим \\
ость
\end{tabular} & \begin{tabular}{|l|} 
Кол-во \\
объектов \\
набл.
\end{tabular} & Коэф. & Значимость & \begin{tabular}{|l|} 
Кол-во \\
объектов \\
набл.
\end{tabular} & Коэф. & Значимость & $\begin{array}{l}\text { Кол-во } \\
\text { объектов } \\
\text { набл. }\end{array}$ & Коэф. & \begin{tabular}{|l|} 
Значим \\
ость \\
\end{tabular} & \begin{tabular}{|l|} 
Кол-во \\
объектов \\
набл.
\end{tabular} \\
\hline $\begin{array}{c}\text { Производительность } \\
\text { труда по ВДС }\end{array}$ &, 035 & 0,500 & 374 &, 032 & 0,535 & 374 & $\begin{array}{l}125 \\
(* *)\end{array}$ & 0,016 & 374 & $\begin{array}{l}, 171 \\
(* * *)\end{array}$ & 0,001 & 374 &, 059 & 0,255 & 374 \\
\hline $\begin{array}{c}\text { Выручка на одного } \\
\text { работника }\end{array}$ & 0,07 & 0,163 & 395 & $\begin{array}{l}128 \\
(* *)\end{array}$ & 0,011 & 395 & $\begin{array}{c}, 087 \\
(*)\end{array}$ & 0,085 & 395 & $\begin{array}{l}133 \\
(* *)\end{array}$ & 0,008 & 395 &, 073 & 0,146 & 395 \\
\hline $\begin{array}{c}\text { Рентабельность } \\
\text { продаж } \\
\end{array}$ & $\begin{array}{l}151 \\
(* *) \\
*\end{array}$ & 0,002 & 398 & $0,091(*)$ & 0,071 & 398 & $\begin{array}{c}174 \\
(* * *) \\
\end{array}$ & 0,000 & 398 & $\begin{array}{c}193 \\
(* * *) \\
\end{array}$ & 0,000 & 398 & \begin{tabular}{|l|}
, 192 \\
$(* * *)$ \\
\end{tabular} & 0,000 & 398 \\
\hline
\end{tabular}

Для оценки использован коэффициент Эта. Статистически значимая связь: ***на уровне $1 \%$, ** на уровне $5 \%$, * на уровне $10 \%$.

Таблица 4

Результаты оценок моделей линейного регрессионного анализа

\begin{tabular}{|c|c|c|c|c|c|c|}
\hline \multirow{2}{*}{ Факторы } & \multicolumn{2}{|c|}{$\begin{array}{c}\text { Производительность } \\
\text { труда по ВДС } \\
\text { (натуральный } \\
\text { логарифм) }\end{array}$} & \multicolumn{2}{|c|}{$\begin{array}{c}\text { Выручка на одного } \\
\text { работника }\end{array}$} & \multicolumn{2}{|c|}{$\begin{array}{c}\text { Рентабельность } \\
\text { продаж }\end{array}$} \\
\hline & $\begin{array}{c}\text { Нестандарт. } \\
\text { коэф. В }\end{array}$ & $\begin{array}{c}\text { Стат.знач. } \\
\text { (t-стат.) }\end{array}$ & $\begin{array}{c}\text { Нестандарт. } \\
\text { коэф. В }\end{array}$ & $\begin{array}{l}\text { Стат.знач. } \\
\text { (t-стат.) }\end{array}$ & $\begin{array}{c}\text { Нестандарт. } \\
\text { коэф. В }\end{array}$ & $\begin{array}{c}\text { Стат.знач. } \\
\text { (t-стат.) }\end{array}$ \\
\hline $\begin{array}{l}\text { Расположение в пределах } \\
\text { агломерации }\end{array}$ &, 365 & $\begin{array}{l}\mathbf{, 0 2 0 * *} \\
(2,344)\end{array}$ & 504,889 & $\begin{array}{c}230 \\
(1,203)\end{array}$ & ,080 & $\begin{array}{l}, 009 * * \\
(2,624) \\
\end{array}$ \\
\hline Участие в Ассоциациях & ,269 & $\begin{array}{c}, 163 \\
(1,398)\end{array}$ & 1654,640 & $\begin{array}{l}\mathbf{0 0 2} * * \\
(3,084)\end{array}$ & ,040 & $\begin{array}{c}, 309 \\
(1,018)\end{array}$ \\
\hline Затраты на НИОКР & ,145 & $\begin{array}{l}\mathbf{0 5 0 * *} \\
(1,970)\end{array}$ & 242,998 & $\begin{array}{l}581 \\
(, 552) \\
\end{array}$ & ,047 & $\begin{array}{c}145 \\
(1,462) \\
\end{array}$ \\
\hline $\begin{array}{l}\text { Участие в совместных } \\
\text { проектах }\end{array}$ & ,174 & $\begin{array}{c}304 \\
(1,029)\end{array}$ & $-28,748$ & $\begin{array}{c}951 \\
(-, 061) \\
\end{array}$ &, 012 & $\begin{array}{l}, 727 \\
(, 349)\end{array}$ \\
\hline $\begin{array}{l}\text { Количество фирм отрасли в } \\
\text { поселении }\end{array}$ & ,001 & $\begin{array}{c}288 \\
(1,064)\end{array}$ &,- 026 & $\begin{array}{c}992 \\
(-, 010)\end{array}$ & ,000 & $\begin{array}{l}, 510 \\
(, 660)\end{array}$ \\
\hline $\begin{array}{l}\text { Инвестиции в основной } \\
\text { капитал }\end{array}$ & $4,858 \mathrm{E}-07$ & $\begin{array}{l}, 000 * * * \\
(4,135)\end{array}$ & ,002 & $\begin{array}{l}, 000 * * * \\
(6,679)\end{array}$ & $6,144 \mathrm{E}-09$ & $\begin{array}{c}, 801 \\
(, 252)\end{array}$ \\
\hline Наличие экспорта &, 544 & $\begin{array}{l}, \mathbf{0 0 1} * * * \\
(3,277)\end{array}$ & 911,218 & $\begin{array}{l}\mathbf{, 0 4 9}^{* *} \\
(1,972)\end{array}$ &, 052 & $\begin{array}{c}121 \\
(1,553) \\
\end{array}$ \\
\hline $\begin{array}{l}\text { Принадлежность к } \\
\text { химической } \\
\text { промышленности }\end{array}$ &,- 081 & $\begin{array}{c}, 711 \\
(-, 371)\end{array}$ & $-658,870$ & $\begin{array}{c}, 241 \\
(-1,174)\end{array}$ &, 015 & $\begin{array}{c}, 707 \\
(0,376)\end{array}$ \\
\hline $\begin{array}{l}\text { Среднесписочная } \\
\text { численность работников }\end{array}$ & $-9,091 \mathrm{E}-05$ & $\begin{array}{c}\mathbf{9 6 1 *} \\
(-1,881) \\
\end{array}$ &,- 396 & $\begin{array}{l}\mathbf{, 0 0 4 * *} \\
(-2,887)\end{array}$ & $2,165 \mathrm{E}-05$ & $\begin{array}{l}\mathbf{0 3 1} * * \\
(2,171)\end{array}$ \\
\hline Константа & 5,081 & $\begin{array}{c}, 000 \\
(33,896)\end{array}$ & 637,852 & $\begin{array}{c}, 110 \\
(1,604)\end{array}$ & ,004 & $\begin{array}{c}\text {,880 } \\
(, 152)\end{array}$ \\
\hline Число наблюдений & \multicolumn{2}{|c|}{344} & \multicolumn{2}{|c|}{378} & \multicolumn{2}{|c|}{377} \\
\hline Prob>F (F-статистика) & 0,000 & $6,170)$ & & & & \\
\hline $\begin{array}{c}\text { R-квадрат (Скоррект. R- } \\
\text { квадрат) }\end{array}$ & \multicolumn{2}{|c|}{, $142(\mathbf{0 , 1 1 9 )}$} & \multicolumn{2}{|c|}{, $147(\mathbf{0 , 1 2 6})$} & \multicolumn{2}{|c|}{$100(\mathbf{0 , 0 7 8})$} \\
\hline Стандартная ошибка & \multicolumn{2}{|c|}{1,14890} & \multicolumn{2}{|c|}{3284,83} & \multicolumn{2}{|c|}{,23846 } \\
\hline
\end{tabular}

Использован тест ANNOVA. Статистическая значимость: *** на уровне $1 \%{ }^{* *}$ на уровне $5 \% *$ на уровне $10 \%$. 